\title{
Wavelength conversion based on cross-phase modulation in a semiconductor Mach- Zehnder modulator
}

Liu, Fenghai; Zheng, Xueyan; Oxenløwe, Leif Katsuo; Pedersen, Rune Johan Skullerud; Jeppesen, Palle; Fraser, J.; Bainbridge, J. D.; Cox, M.

\section{Published in:}

Proceedings of Optical Fiber Communication Conference and Exhibit

Link to article, DOI:

10.1109/OFC.2001.928361

Publication date:

2001

Document Version

Publisher's PDF, also known as Version of record

Link back to DTU Orbit

Citation (APA):

Liu, F., Zheng, X., Oxenløwe, L. K., Pedersen, R. J. S., Jeppesen, P., Fraser, J., Bainbridge, J. D., \& Cox, M. (2001). Wavelength conversion based on cross-phase modulation in a semiconductor Mach-Zehnder modulator. In Proceedings of Optical Fiber Communication Conference and Exhibit (Vol. 3) https://doi.org/10.1109/OFC.2001.928361

\section{General rights}

Copyright and moral rights for the publications made accessible in the public portal are retained by the authors and/or other copyright owners and it is a condition of accessing publications that users recognise and abide by the legal requirements associated with these rights.

- Users may download and print one copy of any publication from the public portal for the purpose of private study or research.

- You may not further distribute the material or use it for any profit-making activity or commercial gain

- You may freely distribute the URL identifying the publication in the public portal 


\title{
Wavelength conversion based on cross-phase modulation in a semiconductor Mach-Zehnder modulator
}

\author{
Fenghai Liu, Xueyan Zheng, Leif Oxenloewe, Rune J.S. Pedersen* and Palle Jeppesen \\ Research Center COM, Technical University of Denmark, Building 349, DK-2800 Lyngby, Denmark \\ Phone: +45-45253845, Fax: +45-45936581, Email: lf@com.dtu.dk \\ * Now with Tellabs Denmark A/S \\ Jim Fraser, John D. Bainbridge and Mike Cox
}

High Performance Optical Component Solutions, Nortel Networks, Brixham Road, Paignton, Devon TQ47BE, United Kingdom Phone: +44-1803-662649, Fax: +44-1803-662917, Email: jimfrasr@nortelnetworks.com

\begin{abstract}
Wavelength conversion based on cross-phase modulation in a reversely biased semiconductor Mach-Zehnder modulator is proposed and successfully demonstrated in a commercial device. The converted signals exhibit extinction ratio $>13 \mathrm{~dB}$ and penalty $<1.5 \mathrm{~dB}$ at $10 \mathrm{~Gb} / \mathrm{s}$ for both NRZ and RZ formats.
\end{abstract}

\section{Introduction:}

Wavelength converters are key components for future advanced optical networks, and several technologies have been used to realize wavelength conversion: opto-electronic conversion, optical wave mixing including four wave mixing and difference frequency generation, optically controlled gating including cross-gain and crossphase modulation in semiconductor optical amplifiers [1,2]. Recently wavelength conversion based on crossabsorption modulation in saturated electroabsorption modulators (EAM) has been reported, showing high conversion speed up to $40 \mathrm{~Gb} / \mathrm{s}$, large wavelength range and regenerative capability [3-5]. However, crossabsorption modulation in EAMs requires high input optical power, which restricts conversion to RZ format with

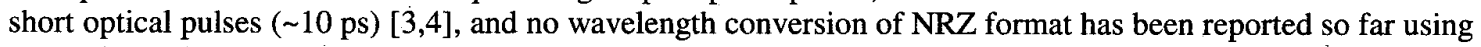
cross-absorption modulation.

In this paper, we explore phase modulation in a reversely biased semiconductor Mach-Zehnder structure and demonstrate wavelength conversion in a commercial InGaAsP Mach-Zehnder modulator (MZM) originally designed as a $10 \mathrm{~Gb} / \mathrm{s}$ transmitter. The converted signals exhibit an extinction ratio better than $13 \mathrm{~dB}$ and a penalty less than $1.5 \mathrm{~dB}$ at $10 \mathrm{~Gb} / \mathrm{s}$ for both $\mathrm{NRZ}$ and $\mathrm{RZ}$ formats.

\section{Principle and basic characteristics:}

Fig. 1(a) shows the schematic diagram of the wavelength converter; the core part is a multiple quantum well (MQW) based InGaAsP Mach-Zehnder modulator. The MZ modulator, which is originally designed as a 10Gb/s transmitter, is fabricated by low-pressure metal organic chemical vapor deposition (MOCVD), and has an active length of the $\mathrm{MZ}$ arms of $600 \mu \mathrm{m}$ [6].

An intensity modulated input signal with wavelength $\lambda_{i}$ is coupled into the asymmetrically biased MZM through an optical circulator, and travels in two arms of the MZM. One of the MZM arms is reversely biased while the other arm is applied a 0 volt bias. The input optical signal in the reversely biased arm is partly absorbed and generates carriers, and the carriers further change the index of that arm. Since the carriers generated by the input signal is roughly proportional to the optical intensity, the intensity modulation of the input signal is transferred into a phase modulation in this arm. The input optical signal in the non-biased arm induces less index change since less light is absorbed. A CW probe light at $\lambda c$, counter-propagating with the input signal, experiences a phase difference between the two arms, and hence becomes intensity modulated at the output of the MZM. The modulated light with wavelength $\lambda c$, i.e., the converted signal, is guided out through the circulator.

An optical isolator is put between the DFB laser and the MZM to prevent the input light from going into the laser. The MZM, DFB laser and optical isolator shown in the dashed frame of Fig. 1(a) are integrated into a compact fibre-pigtailed package together with a wavelength locking scheme. Fig. 1(b) shows a photograph of the packaged device.

Fig. 2. shows the static characteristics of the wavelength converter under different bias conditions. The wavelengths of the CW probe-light and the input signal are $1557.36 \mathrm{~nm}$ and $1550.00 \mathrm{~nm}$, respectively, in all 
experiments. When the left bias is set to $-4.2 \mathrm{~V}$ and right bias to $0 \mathrm{~V}$, the output power of the probe light increases as the input power increases, and the output power changes $10 \mathrm{~dB}$ when the input power increases from $5.8 \mathrm{dBm}$ to $13.8 \mathrm{dBm}$. This indicates a non-inverted wavelength conversion capability with an improvement of the signal extinction ratio. When the right bias is set to $-4.47 \mathrm{~V}$ and the left bias to $0 \mathrm{~V}$, the output power of the probe light decreases as the input power increases. This conversion possibility clearly shows the difference between cross-phase modulation and cross-absorption modulation where the output power always increases as the input power increases.

\section{Wavelength conversion of $10 \mathrm{~Gb} / \mathrm{s} \mathrm{NRZ}$}

The wavelength converter is used to convert a $10 \mathrm{~Gb} / \mathrm{s}$ NRZ signal, which has not been reported using crossabsorption modulation in an EAM. The $10 \mathrm{~Gb} / \mathrm{s}$ optical NRZ signal is generated by a Lithium Niobate external modulator with a pattern length of $2^{31}-1$. After being amplified to an average power of $13.8 \mathrm{dBm}$, the signal is fed into the wavelength converter. The converted eye-diagrams and waveforms detected by a fast photo detector are shown in Fig. 3.

From Fig. 3(a), we can see that the converted $10 \mathrm{~Gb} / \mathrm{s}$ NRZ signal has a wide open eye-diagram and the extinction ratio is better than $13 \mathrm{~dB}$, which is optimised by the bias setting. From Fig. 3(b) and (c), we can see that the converted signal can have either inverted (b) or non-inverted (c) polarity in comparison with the input signal by changing the bias settings of the MZ, which again confirms the phase modulation effect in the MZ modulator. Bit-error-rates (BERs) of the converted signal and the input signal measured using an optically preamplified receiver are shown in Fig. 4. Power penalties less than $1.5 \mathrm{~dB}$ at $\mathrm{BER}=10^{-9}$ can be found from Fig.4.

\section{Wavelength conversion of $10 \mathrm{~Gb} / \mathrm{s} . \mathrm{RZ}$}

The wavelength converter is also used to convert a $10 \mathrm{~Gb} / \mathrm{s} \mathrm{RZ}$ signal. The $10 \mathrm{~Gb} / \mathrm{s}$ optical $\mathrm{RZ}$ signal is obtained by externally modulating the optical light source with an electrical RZ signal using the Lithium Niobate modulator [7]. The FWHM pulse-width of the $10 \mathrm{~Gb} / \mathrm{s} \mathrm{RZ}$ optical signal is about $40 \mathrm{ps}$. The converted signal is detected using the same photo detector. Fig. 5 shows the eye-diagrams of input signal in (a) and converted signal in (b). Comparing the two eye-diagrams, no obvious pulse-broadening after wavelength conversion can be found, which indicates a fast conversion feature of the device. The extinction ratio of the converted signal is also better than $13 \mathrm{~dB}$. Measured BER curves of input signal and converted signal are shown in Fig. 6 using the same receiver, and power penalties less than $1.5 \mathrm{~dB}$ at $\mathrm{BER}=10^{-9}$ can be found.

\section{Conclusion}

Wavelength conversion based on cross-phase modulation in a reversely biased semiconductor MZ modulator has been proposed and successfully demonstrated at $10 \mathrm{~Gb} / \mathrm{s}$ for both NRZ and RZ formats using a compact wavelength stabilised commercially available $10 \mathrm{~Gb} / \mathrm{s}$ transmitter. The experimental results show that wavelength conversion based on cross-phase modulation in reversely biased semiconductor MZ modulators can be realized at high speed for both NRZ and RZ.

\section{Reference}

[1] S.J. Yoo, "Wavelength conversion technologies for WDM network applications", J. of Lightwave Technology, vol. 14 (6), 1996. pp. 955-966.

[2] K. E. Stubkjaer, A. Kloch, P. B. Hansen, H. N. Poulsen, D. Wolfson, K. S. Jepsen, A. T. Clausen, E. Limal and A. Buxens: "Wavelength converter technology", IEICE Transactions on Communications, vol. E82-B (2), 1999. pp.390-400.

[3] N. Edagawa, M. Suzuki, S. Yamamoto, S. Akiba: "Novel wavelength converter using an electroabsorption modulator: conversion experiments at up to $40 \mathrm{~Gb} / \mathrm{s}^{\prime}$, OFC'97, pp.77-78.

[4] L.K. Oxenloewe, A.T. Clausen and H.N. Poulsen: "Wavelength conversion in an electroabsorption modulator", ECOC'2000, Vol.3, pp.303-304.

[5] T. Miyazaki, N. Edagawa, M. Suzuki, and S. Yamamoto, "Novel optical regenerator using electroabsorption modulator", $O F C^{\prime} 99$, vol.2, pp350-352.

[6] C. Rolland: "InGaAsP-based Mach-Zehnder modulators for high-speed transmission systems", OFC'98, 1998, pp.283-284.

[7]. F. Liu, C. Peucheret, X. Zheng, R.J.S. Pedersen and P. Jeppesen: "A novel chirped RZ transmitter and transmission experiments"; ECOC'2000. pp. 113-114. 
WK4-3

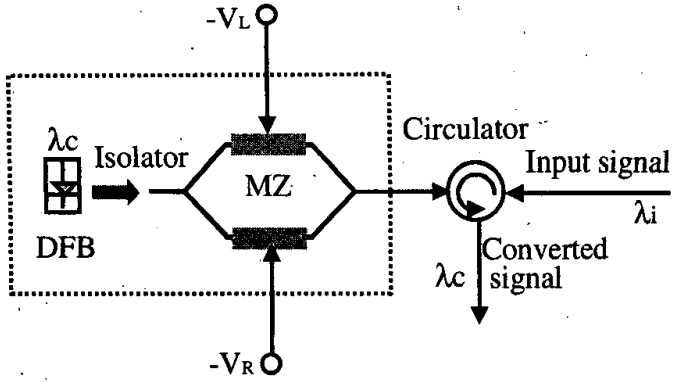

(a)

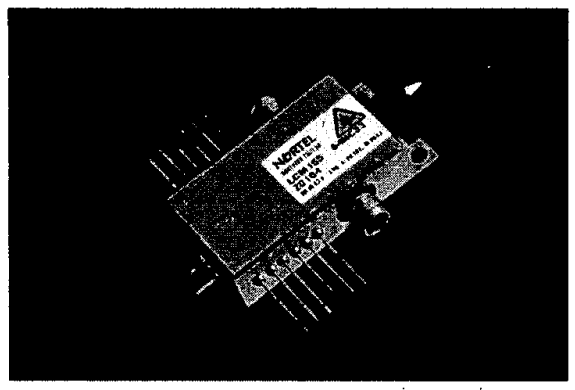

(b)

Fig. 1. Schematic diagram (a) and photograph (b) of the wavelength converter. MZ: InGaAsP Mach-Zehnder modulator.

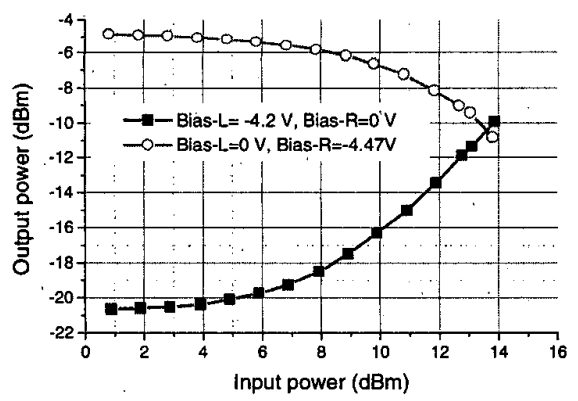

Fig. 2. Static characteristics of the wavelength converter.

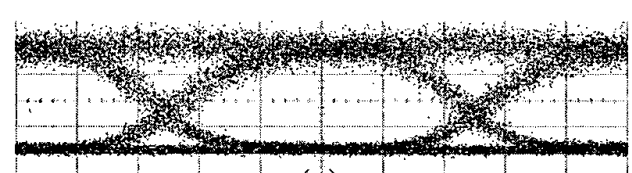

(a)

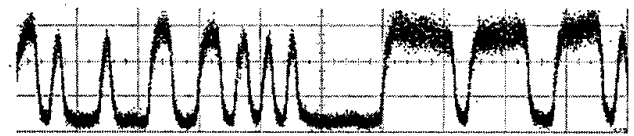

(b)

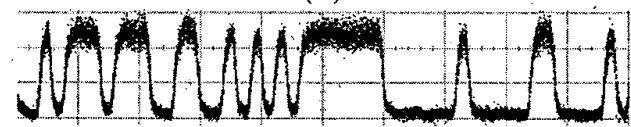

(c)

Fig. 3. Eye-diagrams (a) and waveforms $(b, c)$ of the converted signals of $10 \mathrm{~Gb} / \mathrm{s}$ NRZ. (b) Inverted conversion. (c) Non-inverted conversion.

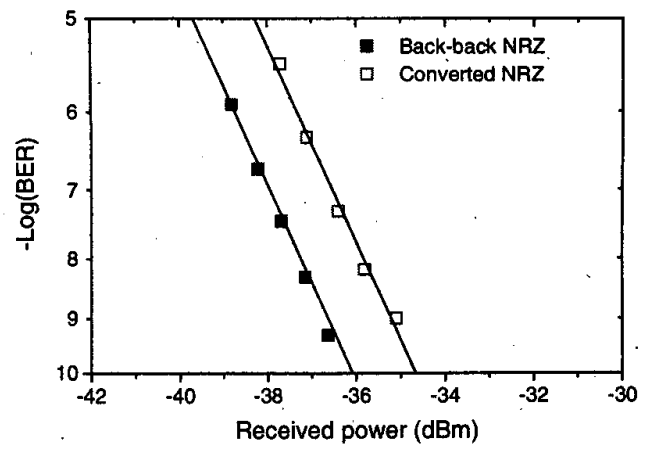

Fig. 4. BER curves of wavelength conversion of $10 \mathrm{~Gb} / \mathrm{s} \mathrm{NRZ}$ signal.

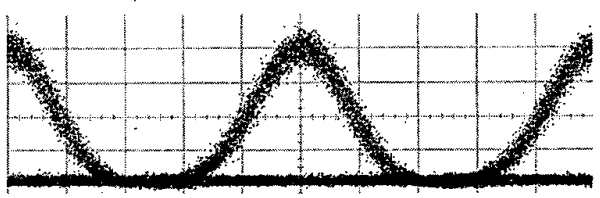

(a)

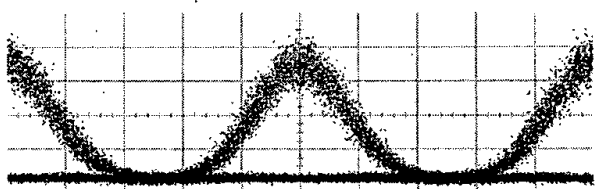

(b)

Fig. 5. Eye-diagrams of input signal (a) and converted signal (b).

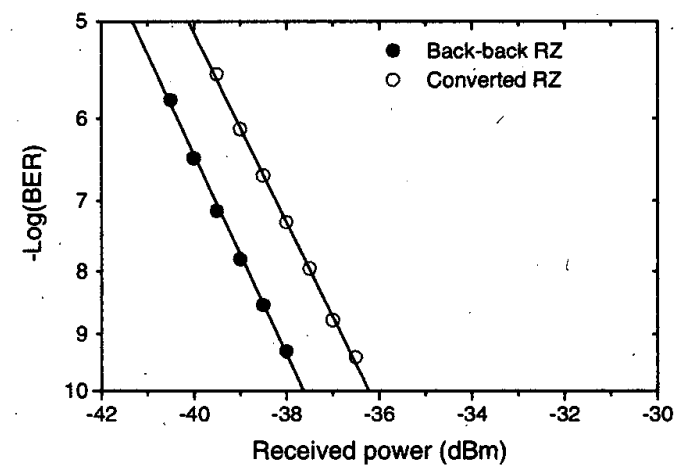

Fig. 6. BER curves of wavelength conversion of $10 \mathrm{~Gb} / \mathrm{s} \mathrm{RZ}$ signal. 